\title{
Exame do CFC e Educação Contábil: Análise das características das IES e seus índices de aprovação
}

\author{
Deivson Vinicius Barroso \\ https://orcid.org/0000-0001-6412-0165 | E-mail:deivson.vinicius07@gmail.com \\ Sheizi Calheira de Freitas \\ https://orcid.org/0000-0002-1148-4296 | E-mail: shecal@ufba.br \\ José Sérgio Casé de Oliveira \\ https://orcid.org/0000-0003-3031-4943 | E-mail:js_cdo@hotmail.com
}

\section{Resumo}

Objetivo: verificar quais características das Instituições de Ensino Superior (IES) estão relacionadas à aprovação dos seus alunos no Exame de Suficiência do CFC.

Método: Foram analisadas características institucionais de 741 instituições presentes no Exame nas duas edições de 2017. Para o tratamento dos dados, foi utilizada a análise de Regressão Beta Inflacionada.

Resultados: Verificou-se que as características institucionais que se mostraram positivamente correlacionadas com maiores índices de aprovação das IES no exame do CFC foram: nota do Enade; conceito IGC; pertencer a uma universidade pública; estar localizado em capitais dos estados brasileiros; ser citado no Ranking Universitário Folha; e possuir programas de pós-graduação em Contabilidade. Por sua vez, mostraram-se negativamente correlacionadas: Regime de Trabalho dos Professores, Organização Acadêmica e localização da IES nas regiões Centro-Oeste, Nordeste e Norte.

Contribuições: A expansão de cursos de Ciências Contábeis no país não pode estar dissociada da obtenção do conhecimento necessário ao desenvolvimento da atividade profissional, conforme sugere resultado da variável exploratória RUF. A partir dos resultados encontrados possibilita-se que os gestores das IES conheçam quais atributos institucionais contribuem para o bom desempenho no Exame, propiciando a melhor gestão dos fatores passíveis de modificação, o que se espera resultar também em melhoria da formação contábil.

Palavras-chave: Ensino Superior, Instituições de Ensino Superior, Cursos de Contabilidade, Exame do CFC. 


\section{Introdução}

O estudo do desempenho dos estudantes de Contabilidade em exames profissionais tem sido objeto de trabalhos acadêmicos internacionais. Fogarty, Zimmerman e Richardson (2016) estudaram essa relação e constataram que os resultados dos exames profissionais são levados em consideração pelos docentes em universidades ao avaliarem a qualidade dos cursos de contabilidade nos Estados Unidos.

Na mesma linha, Morgan, Bergin e Sallee (2012) concluíram que os estudantes dos cursos de contabilidade classificados como de alta qualidade por uma associação de acreditação de qualidade educacional americana alcançavam, de maneira significativa, maiores taxas de aprovação no exame profissional $C P A$. Essa relação positiva entre as taxas de aprovação no CPA e os níveis de acreditação da qualidade das Instituições de Ensino Superior (IES) foi, do mesmo modo, encontrada por Morgan, Bergin e Sallee (2008).

No Brasil, o Exame de Suficiência do Conselho Federal de Contabilidade (CFC) corresponde ao meio de acesso à certificação profissional necessária ao desempenho da atividade contábil. Por sua vez, os resultados recentes dos exames profissionais realizados pelos egressos do curso revelam desempenhos cada vez menores ao longo dos anos, no que tange às taxas de aprovação.

Em relatório estatístico, o Conselho Federal de Contabilidade evidencia que, entre os anos $2011 \mathrm{e}$ 2017, em média, apenas 35,87\% dos formandos que realizaram o Exame foram aprovados. Na edição mais recente $-1^{\text {a }}$ edição de 2019 -, o resultado revela-se bastante desanimador: 65,07\% dos candidatos foram reprovados no exame (CFC, 2019).

Como resultado dos programas de expansão de universidades e cursos superiores adotados pelo Governo brasileiro, o curso de Ciências Contábeis se popularizou, tornando-se o quarto curso mais procurado nas redes privadas de ensino superior. No ano de 2006, havia 57.257 alunos em cursos de Contabilidade no país (INEP, 2007), enquanto que, em 2018 este número correspondia a 359.840 alunos matriculados em cursos "presenciais" e a "distância" de Ciências Contábeis (INEP, 2019).

A partir dessas constatações, e entendendo que o Exame de Suficiência representa, no curso de Contabilidade, um passo importante para a carreira dos egressos e uma preocupação dos estudantes bacharéis, acredita-se ser importante conhecer quais elementos podem estar associados ao desempenho no exame. Em contexto internacional, as instituições e programas de Contabilidade que possuam alunos egressos com desempenho satisfatório em resultados de exames profissionais podem vir a ter maior reconhecimento no mercado de trabalho (Fogarty, Zimmerman \& Richardson, 2016).

Entretanto, no Brasil, ainda não existem evidências sobre a existência de relação entre o desempenho de egressos do curso de Contabilidade no exame de certificação profissional e a sua receptividade pelo mercado de trabalho, algo que também se pretende verificar na presente proposta por meio de variável exploratória, contribuindo-se, dessa forma, com a literatura nacional da área de educação contábil.

No ano de 2017, o Conselho Federal de Contabilidade disponibilizou dados estatísticos do desempenho dos estudantes de Contabilidade no Exame de Suficiência por Instituição de Ensino Superior, sendo possível, portanto, verificar quais características das IES estariam relacionadas à aprovação dos seus egressos no Exame de Suficiência da profissão contábil. A partir do exposto, tem-se o seguinte problema de pesquisa: Quais são os fatores institucionais associados a aprovação de bacharéis em Ciências Contábeis no Exame de Suficiência do CFC?

Estudos na área contábil com foco no Exame de Suficiência profissional do CFC são demasiadamente escassos, principalmente porque o órgão não divulgava regularmente os resultados por IES, até 2017, o contrário do que ocorria com os dados doEnade, que vêm sendo divulgados anualmente desde 2004. Por conta disso, é possível encontrar na literatura nacional acerca da educação contábil diversas características institucionais relacionadas, positivamente ou negativamente, ao desempenho obtido pelos discentes do curso de Ciências Contábeis no exame que se propõe a avaliar a qualidade do ensino superior brasileiro (Enade), porém, o mesmo fato não ocorre quando o instrumento de verificação utilizado é o Exame de Suficiência. 
A partir do exposto, espera-se contribuir com a literatura da área de educação e pesquisa em Contabilidade, possibilitando que fatores institucionais associados aos índices de aprovação no exame do CFC sejam conhecidos e confrontados com resultados de outros trabalhos, nacionais e internacionais, relacionados a desempenho discente e formação em Contabilidade. Paralelamente, será verificado também quais fatores contribuem de forma mais significativa para percentuais elevados de aprovação e reprovação no exame do CFC.

Por fim, objetiva-se, a partir dos resultados encontrados no presente estudo, possibilitar ainda que os gestores das IES conheçam quais atributos institucionais contribuem para o bom desempenho de seus discentes no exame, que possibilita o exercício da profissão contábil no Brasil, de modo que estes possam trabalhar no sentido de maximizar suas taxas de aprovação por meio do gerenciamento de fatores que sejam passíveis de modificação.

\section{Revisão de Literatura}

\subsection{Perspectiva Histórica}

O ensino profissional de Contabilidade no Brasil firma suas primeiras raízes com a chegada da Corte Portuguesa no início do século XIX, quando em 1809 são instituídas as primeiras aulas de Comércio no Brasil. Ações da Coroa, como a abertura dos portos às "nações amigas" e a diversificação de mercadorias e formas de comércio no país inaugurou, em solo nacional, o uso de técnicas contábeis básicas como o Método das Partidas Dobradas e, consequentemente, o uso de livros contábeis para a escrituração comercial (Oliveira, 2010).

No início do século XX, em 1902, conforme destaca Nossa (1999), o ensino contábil no Brasil foi marcado pela criação da Escola Prática de Comércio de São Paulo, posteriormente denominada Escola de Comércio Álvares Penteado. Por meio da conclusão deste curso, era possível alcançar o título de Contador, que foi substituído em 1926, pelo Decreto n. ${ }^{\circ}$ 17.329, pela graduação em Ciências Econômicas e Comerciais.

Silva (2004, p. 34) explica que em 1931, o Decreto n² 20.158 "instituiu o curso Técnico de Contabilidade, com duração de dois anos, para formar Guarda-livros e, de três anos, para formar Peritos Contadores”. O autor ressalta que, apenas em 1945, o Decreto-Lei nº 7.988 institui o curso de Ciências Contábeis e Atuariais, sendo a primeira turma formada em 1949, na Fundação Álvares Penteado (Silva, 2004).

Saes e Cytrynowicz (2001) relatam que a criação do curso de Ciências Contábeis e Atuariais contribuiu para, em 1946, a instituição da Faculdade de Ciências Econômicas e Administrativas/FEA da Universidade de São Paulo (USP), que lançou as bases do primeiro núcleo de pesquisa contábil no Brasil, com relevantes contribuições para a área. Posteriormente, esta instituição originou o primeiro curso de pós-graduação stricto sensu em Contabilidade do país.

Também, em 1946, foi criado o Conselho Federal de Contabilidade (CFC), uma autarquia especial dotada de personalidade jurídica de direito público que aprova o Regulamento Geral dos Conselhos de Contabilidade em todo o Brasil, e possui como objetivo, entre outras finalidades, "orientar, normatizar e fiscalizar o exercício da profissão contábil, por intermédio dos Conselhos Regionais de Contabilidade" (CFC, 2017). O Conselho, a partir da Lei no 12.249, de 2010, também é responsável por regulamentar o Programa de Educação Profissional Continuada para os profissionais da contabilidade, definindo ações para viabilizar, controlar e fiscalizar o cumprimento do Programa pelos membros do Conselho (CFC, 2016).

Em 1998, de acordo com Nossa (1999), já existiam 384 cursos superiores de Contabilidade no país. $\mathrm{Na}$ época, deste número, " $41,4 \%$ estão localizados nas universidades, sendo $49 \%$ nas públicas e $51 \%$ nas privadas. Os estabelecimentos isolados, federações e faculdades integradas contam com $58,6 \%$ dos cursos, sendo 15\% em instituições públicas e $85 \%$ em privadas" (Nossa, 1999, p. 38). 
É, porém, a partir do século XXI que o número de universidades e cursos superiores no Brasil cresce de maneira acelerada. Tal crescimento esteve associado ao desenvolvimento econômico e consequente surgimento de empresas e outras atividades comerciais, ao processo de globalização e a acessibilidade às informações causada pelo surgimento de novas tecnologias, além da inserção do país em ambientes internacionais. Adicionalmente, nos últimos anos, políticas públicas de interiorização e expansão da educação superior culminaram no aumento da oferta de vagas em cursos de Contabilidade no Brasil. Atualmente, são 1.489 cursos de Contabilidade oferecidos em todo país nas modalidades "presencial" e a "distância" (INEP, 2019).

Com o objetivo de verificar a obtenção de conhecimentos referentes a conteúdos desenvolvidos no curso realizado, tornou-se requisito para obtenção do registro profissional contábil, por meio da Lei n. ${ }^{\circ}$ 12.249/2010, posteriormente regulamentada pela Resolução CFC n. ${ }^{\circ} 1.486 / 2015$, a aprovação no Exame de Suficiência da profissão, realizado duas vezes por ano nos dias atuais.

\subsection{Estudos Anteriores}

Entre os escassos esforços recentes, que se propuseram a estudar aspectos relacionados ao Exame de Suficiência do CFC, destacam-se os trabalhos de Rodrigues, Pinho, Bugarim, Craig e Machado (2018) e o de Bugarim, Rodrigues, Pinho e Machado (2014). Esses primeiros, utilizaram regressão logística para identificar fatores associados a aprovação de egressos de cursos de contabilidade no Exame de Suficiência do CFC realizado no ano de 2012, e constataram que candidatos do sexo masculino, a região do país em que realizaram o curso, a qualidade da IES e a idade dos egressos se mostraram positivamente correlacionados com o bom desempenho no exame.

Por sua vez, Bugarim et al.(2014), a partir de uma análise de conglomerados, analisaram o desempenho dos candidatos no Exame de Suficiência por áreas de conhecimento contábil versus as unidades federativas brasileiras, que nos resultados foram divididas em dois grupos (de maior percentual de acerto e de menor percentual de acerto), nos quais tais unidades foram reunidas.

Nos Estados Unidos, o exercício da profissão contábil também é vinculado à aprovação em um exame de certificação internacionalmente conhecido como CPA. Acerca do desempenho de bacharéis em Ciências Contábeis no referido exame, diferente do que ocorre no cenário brasileiro, estudos diversos podem ser encontrados na literatura. Bline et al. (2015) buscaram identificar associações entre caraterísticas dos docentes de Contabilidade e o desempenho discente no exame CPA, concluindo que cursos com altos percentuais de docentes com expertise nas áreas abordadas no exame, a produtividade em pesquisa $\mathrm{e}$ a existência de docentes certificados no exame CPA são fatores correlacionados positivamente com o desempenho discente no exame.

Em outro estudo, Bunker e Harris (2014) estudaram a relação entre modalidade de ensino contábil e as taxas de aprovação no exame CPA, em que constataram que egressos provenientes de cursos predominantemente "a distância" obtiveram desempenho significativamente inferior do que egressos oriundos de cursos presenciais e/ou tradicionais.

Ainda abordando taxas de aprovação no exame CPA, Briggs e He (2012) avaliaram se as diferentes exigências existentes nos estados americanos, no que tange à carga horária de educação superior necessária para inscrição no exame CPA, têm relação com a taxa de aprovação no referido exame, obtendo resultados inconclusivos, dada a variabilidade de desempenho por área de especialização contábil, assim como por destaque de alguns estados com menor carga horária exigida.

Por fim, ainda a título de exemplo, Barilla, Jackson e Mooney (2008) compararam o desempenho entre egressos de instituições de ensino superior credenciadas a uma associação de escolas de negócios americana e egressos oriundos de outras instituições, verificando que as chances de aprovação, na primeira tentativa, no exame CPA. são correlacionadas com a origem institucional dos candidatos. 


\section{Metodologia}

Dos 1.684 cursos superiores de Ciências Contábeis em atividade em 2017, 1.524 IES tiveram alunos realizando o Exame de Suficiência para contador no $1^{\circ}$ semestre de 2017 e 1.581 IES na segunda edição do mesmo ano, de acordo com as planilhas Relação do Resultado Geral por IES disponibilizadas pelo Conselho Federal de Contabilidade. O total de IES com alunos realizando o exame em cada edição de 2017 representa a população deste estudo.

Para constituição da amostra foram realizados dois filtros iniciais. Primeiramente, foram identificados os cursos das IES que apresentaram candidatos inscritos nas duas edições do exame em 2017, uma vez que o estudo abrange esse espaço temporal. Posteriormente, foram selecionados apenas os cursos que possuíam, pelo menos, dez (inclusive) candidatos inscritos em cada uma das edições, uma vez que os cursos das IES com número de inscritos inferior a dez seriam potenciais outliers, dado que se verificou, por exemplo, que das IES que tiveram menos de 10 alunos realizando a $1^{\text {a }}$ edição do exame, 297 apresentaram índices de aprovação igual a $0 \%$. O mesmo filtro foi realizado na $2^{\text {a }}$ edição e, desta vez, 270 IES com menos de 10 alunos realizando o exame obtiveram também índice igual a $0 \%$ de aprovação.

Assim, foram objeto de análise neste estudo, 741 cursos de Ciências Contábeis de Instituições de Ensino Superior com pelo menos dez participantes nas duas edições do Exame de Suficiência em 2017. Essa amostra representava 44\% dos cursos de Ciências Contábeis em funcionamento no país em dezembro de 2017.

A fase inicial para a análise dos dados se deu a partir da verificação das estatísticas descritivas das variáveis. Após tal análise, foram estimados modelos de regressão beta inflacionados com dados institucionais das IES. A regressão beta inflacionada em 0 e 0 e 1 é a técnica que mais se adequa aos dados da pesquisa por ser a variável dependente um indicador que representa taxa de aprovação (aprovação no exame do CFC), possuindo intervalo de variação de 0 a 1 , não permitindo resultados negativos, ou valores superiores a $1(100 \%)$.

Conforme explicam Ferrari e Cribari-Neto (2004), a regressão beta é indicada quando a variável dependente é beta distribuída (intervalo de 0 a 1). Além disso, segundo Ospina e Ferrari (2010), quando um intervalo de variação beta apresenta dados com valores de 0 e/ou 1, necessita-se aplicar a regressão beta inflacionada, podendo esta ser inflacionada em 0 , em 1 , ou em 0 e 1 , caso existam dados na amostra que representem percentual zero, cem, ou ambos, respectivamente.

Como na $1^{\text {a }}$ edição do exame em 2017, existem cursos que apresentaram $0 \%$ de aprovação e cursos que apresentaram 100\% de aprovação foi utilizada a Regressão Beta Inflacionada em 0 e 1. Já na 2a edição, havia instituições com $0 \%$ de alunos aprovados, porém nenhuma com $100 \%$ de aprovação, portanto, o modelo foi estimado por meio da Regressão Beta Inflacionada em 0. Para os submodelos utilizados na regressão, foram utilizadas as funções de ligação log e logit, funções de ligação default do pacote gamlss, disponível no CRAN. Os testes estatísticos propostos foram realizados através do Software "R".

Destaca-se que, previamente, procedeu-se a uma análise de regressão com estimador MQO, sendo identificada heterocedasticidade no modelo. O problema, entretanto, é resolvido pela regressão beta inflacionada, por ser este um modelo robusto à heterocedasticidade, uma vez que modela a média e a precisão.

A variável dependente (CFC) desta pesquisa é o Índice de Aprovação no Exame de Suficiência de Contabilidade (edição 2017/1 e 2017/2) por Instituição de Ensino Superior. O Índice de Aprovação por IES, da primeira e da segunda edições de 2017 do Exame de Suficiência em Contabilidade foi disponibilizado pelo Conselho Federal de Contabilidade no site do órgão, por meio da Planilha "Relação Apuração Resultado Geral por IES”.

Para a definição das variáveis independentes, buscou-se verificar na literatura quais eram os principais fatores institucionais associados ao desempenho de estudantes de ciências contábeis utilizados em trabalhos anteriores com o objetivo de conhecer os atributos mais pesquisados, nacional e internacionalmente, quando se objetiva relacionar características institucionais ao desempenho em exames. As variáveis independentes, bem como os trabalhos que lhes deram origem, são apresentados na Tabela 1. 
Tabela 1

Variáveis independentes

\begin{tabular}{|c|c|c|c|c|}
\hline Variável & Sigla & Mensuração & Fundamentação & Base de Dados \\
\hline $\begin{array}{l}\text { Desempenho do } \\
\text { Curso no ENADE }\end{array}$ & ENADE & Nota contínua de 0 a 5 & $\begin{array}{l}\text { Lemose Miranda (2014); } \\
\text { Ferreira (2015); Santos (2012); } \\
\text { Pandolfi (2017). }\end{array}$ & $\begin{array}{l}\text { Conceito } \\
\text { Preliminar de } \\
\text { Curso (CPC) } \\
2015\end{array}$ \\
\hline Infraestrutura & INFR & Nota Padronizada de 0 a 5 & $\begin{array}{l}\text { Andriola (2009); Moreira (2010); } \\
\text { Lemos e } \\
\text { Miranda (2014); Ferreira (2015); } \\
\text { Lacerda (2015) }\end{array}$ & CPC 2015 \\
\hline $\mathrm{N}^{\circ}$ de Docentes & PROF & $\begin{array}{l}N^{\circ} \text { Docentes atuantes na IES (de } 0 \\
\text { a 163) }\end{array}$ & $\begin{array}{l}\text { Abjaud (2014); Lepchak, } \\
\text { Oliveira, Fragalli e Scarpin } \\
\text { (2016). Pandolfi (2017). }\end{array}$ & CPC 2015 \\
\hline $\begin{array}{l}\text { Titulação do } \\
\text { Corpo Docente }\end{array}$ & DOC & Nota Padronizada de 0 a 5 & $\begin{array}{l}\text { Moreira (2010); Santos (2012); } \\
\text { Lemos e Miranda (2014); Cruz } \\
\text { (2012). }\end{array}$ & CPC 2015 \\
\hline $\begin{array}{l}\text { Regime de } \\
\text { Trabalho dos } \\
\text { Professores }\end{array}$ & REGIM & Nota Padronizada de 0 a 5 & $\begin{array}{c}\text { Santos (2012); Lemos e } \\
\text { Miranda (2014); Lacerda (2015). }\end{array}$ & CPC 2015 \\
\hline $\begin{array}{l}\text { Carga Horária } \\
\text { do curso }\end{array}$ & HORA & Carga Horária Total do curso & Variável exploratória & $\begin{array}{l}\text { Censo da } \\
\text { Educação } \\
\text { Superior de } \\
2016\end{array}$ \\
\hline $\begin{array}{l}N^{\circ} \text { de matrículas } \\
\text { no curso }\end{array}$ & MAT & $\begin{array}{l}\text { Número de Matrículas realizadas } \\
\text { em } 2016\end{array}$ & $\begin{array}{c}\text { Andriola (2009); Abjaud (2014); } \\
\text { Lepchak, et al. (2016); Pandolfi } \\
\text { (2017). }\end{array}$ & $\begin{array}{l}\text { Censo da } \\
\text { Educação } \\
\text { Superior de } \\
2016\end{array}$ \\
\hline $\begin{array}{l}\text { Tempo de } \\
\text { Existência do } \\
\text { Curso }\end{array}$ & AGE & $\begin{array}{l}N^{\circ} \text { de anos de funcionamento do } \\
\text { curso na IES }\end{array}$ & Lepchak et al. (2016). & $\begin{array}{l}\text { Censo da } \\
\text { Educação } \\
\text { Superior de } \\
2016\end{array}$ \\
\hline Região & REG & $\begin{array}{c}\text { Variável dummy: } \\
0 \text { - Sudeste (constante); } \\
1 \text { - Centro-Oeste; } 1 \text { - Nordeste; } 1 \text { - } \\
\text { Norte; } 1 \text { - Sul }\end{array}$ & $\begin{array}{l}\text { Cruz, Moreira (2010); Cruz } \\
\text { (2012); Abjaud (2014). }\end{array}$ & $\begin{array}{c}\text { Censo da } \\
\text { Educação } \\
\text { Superior de } \\
2016\end{array}$ \\
\hline $\begin{array}{l}\text { Organização } \\
\text { Acadêmica }\end{array}$ & ORG & $\begin{array}{c}\text { Variável dummy: } \\
0 \text { - Universidade (constante); } 1 \text { - } \\
\text { Centro Universitário; } 1 \text { - Faculdade; } \\
1 \text { - Instituto Federal }\end{array}$ & Moreira (2010); Abjaud (2014). & $\begin{array}{l}\text { Censo da } \\
\text { Educação } \\
\text { Superior de } \\
2016\end{array}$ \\
\hline $\begin{array}{c}\text { Categoria } \\
\text { Administrativa }\end{array}$ & CAT & $\begin{array}{l}\text { Variável dummy: } \\
0 \text { - Privada; } 1 \text { - Pública }\end{array}$ & $\begin{array}{l}\text { Moreira (2010); Cruz (2012); } \\
\text { Abjaud (2014). }\end{array}$ & $\begin{array}{l}\text { Censo da } \\
\text { Educação } \\
\text { Superior de } \\
2016\end{array}$ \\
\hline $\begin{array}{l}\text { Cursos em } \\
\text { Capitais }\end{array}$ & IN_CAP & $\begin{array}{c}\text { Variável dummy: } \\
0 \text { - IES não está localizada em } \\
\text { capital; } \\
1 \text { - IES está localizada em capital. }\end{array}$ & Variável exploratória & $\begin{array}{c}\text { Censo da } \\
\text { Educação } \\
\text { Superior de } \\
2016\end{array}$ \\
\hline $\begin{array}{l}\text { IES com Pós } \\
\text { Stricto Sensu }\end{array}$ & PÓs & $\begin{array}{c}\text { Variável dummy: } \\
0 \text { - IES não possui curso Stricto } \\
\text { Sensu em Contabilidade } \\
1 \text { - IES possui curso Stricto Sensu } \\
\text { em Contabilidade }\end{array}$ & Variável exploratória & $\begin{array}{l}\text { Plataforma } \\
\text { Sucupira }\end{array}$ \\
\hline $\begin{array}{l}\text { Abertura do } \\
\text { Mercado }\end{array}$ & RUF & $\begin{array}{c}\text { Variável dummy: } \\
0 \text { - IES ausente no Ranking de } \\
\text { empregadores RUF } \\
1 \text { - IES presente no Ranking de } \\
\text { empregadores RUF }\end{array}$ & Variável exploratória & $\begin{array}{l}\text { Ranking } \\
\text { Universitário da } \\
\text { Folha } 2018\end{array}$ \\
\hline Efeito Halo & HALO & IGC contínuo - 1 a 5 & $\begin{array}{l}\text { Fogarty, Zimmerman, } \\
\text { Richardson (2016). }\end{array}$ & IGC 2016 \\
\hline
\end{tabular}

Fonte: elaboração própria (2018). 


\section{Resultados}

\subsection{Estatísticas Descritivas da Variável Dependente}

A primeira variável analisada, conforme Tabela 2, foi a variável dependente do Estudo, o Índice de Aprovação no Exame de Suficiência Profissional de Contabilidade (CFC).

Tabela 2

\section{Estatísticas Descritivas}

\begin{tabular}{cccccccc}
\hline N: 741 IES & Média & Mediana & Moda & Variância & Desvio Padrão & Mínimo & Máximo \\
\hline $\begin{array}{l}1^{\text {a }} \text { Edição } \\
\text { CFC/2017 }\end{array}$ & $27,57 \%$ & $25,00 \%$ & $0,00 \%$ & 325,241 & 18,034 & $0,00 \%$ & $100,00 \%$ \\
\hline $\begin{array}{l}2^{\text {a }} \text { Edição } \\
\text { CFC/2017 }\end{array}$ & $28,42 \%$ & $25,00 \%$ & $20,00 \%$ & 309,484 & 17,592 & $0,00 \%$ & $97,14 \%$ \\
\hline
\end{tabular}

Fonte: resultados da Pesquisa.

Na primeira edição, destaca-se a média de $27,57 \%$ de aprovação dos alunos dos cursos das IES da amostra que prestaram o exame. Tal resultado é levemente superior à média de todos os 1524 cursos que tiveram alunos realizando a $1^{\text {a }}$ edição do CFC em 2017, que foi de $25,26 \%$, e inferior à média geral de aprovados desde a $1^{\text {a }}$ edição de 2011 , que é de $35,87 \%$. A média de aprovação entre os cursos estudados aumenta suavemente na $2^{\text {a }}$ edição do exame: $28,41 \%$ de aprovados.

Foram verificadas também as estatísticas descritivas das variáveis independentes em relatórios não reportados. Tais variáveis apresentaram valores condizentes com os verificados na literatura da área.

\subsection{Resultados Regressão Beta Inflacionada em 0 e em 0 e 1}

Os resultados apresentados a seguir foram obtidos a partir de um procedimento exaustivo de comparação de diversos modelos ajustados, levando em consideração diferentes combinações possíveis de variáveis independentes. São reportados e analisados os resultados provenientes dos modelos com melhor ajuste, segundo os critérios AIC e SBC.

Informa-se ainda que não foram identificados problemas de multicolinearidade entre as variáveis e que, diferentemente de modelos estimados via MQO, a regressão beta inflacionada, por ser um modelo baseado em verossimilhança, não necessita de vários pressupostos para atestar sua validade, tendo como principal hipótese, que a variável modelada segue a distribuição assumida para estimação.

\subsubsection{Regressão Principal}

Para a $1^{\text {a }}$ edição do Exame de Suficiência foi utilizada a Regressão Beta inflacionada em 0 e 1 , visto que nesta edição tivemos cursos com $0 \%$ e $100 \%$ de aprovação no exame. Já na $2^{\mathrm{a}}$ edição do exame, foi executada a Regressão Beta Inflacionada em 0 , uma vez que nesta edição tivemos cursos com $0 \%$ de aprovação, mas nenhum com $100 \%$ dos candidatos aprovados.

A Tabela 3 revela as variáveis que possuem significância estatística para explicar o desempenho médio das IES na $1^{\text {a }}$ edição do Exame, enquanto a Tabela 4 apresenta as variáveis estatisticamente significantes na $2^{\mathrm{a}}$ edição do exame. 
Tabela 03

Outputs Regressão Beta Inflacionada em 0 e 1 - 1ª Edição 2017

\begin{tabular}{|c|c|c|c|c|}
\hline Variáveis & Estimativa & Erro Padrão & Valor t & Significância \\
\hline (Intercepto) & -193.591 & 0.15505 & -12.486 & $\star \star \star$ \\
\hline ENADE & 0.37220 & 0.03510 & 10.605 & $\star \star \star$ \\
\hline INFR & -0.04717 & 0.02188 & -2.156 & * \\
\hline DOC & 0.05891 & 0.02381 & 2.474 & $\star$ \\
\hline REGIM & -0.08842 & 0.02017 & -4.383 & $\star \star \star ~$ \\
\hline HALO & 0.12291 & 0.05602 & 2.194 & * \\
\hline CAT & 0.35309 & 0.08608 & 4.102 & $\star \star \star$ \\
\hline Dummy_ORG_FAC & -0.19094 & 0.05535 & -3.450 & $\star \star \star$ \\
\hline Dummy_Reg_CentroOeste & -0.39723 & 0.07773 & -5.111 & $\star \star \star$ \\
\hline Dummy_Reg_Nordeste & -0.29683 & 0.06362 & -4.666 & $\star \star \star$ \\
\hline Dummy_Reg_Norte & -0.54872 & 0.09162 & -5.989 & $\star \star \star$ \\
\hline Dummy_Reg_Sul & 0.11141 & 0.05913 & 1.884 & . \\
\hline IN_CAP & 0.12801 & 0.04850 & 2.640 & $\star \star$ \\
\hline RUF & 0.20565 & 0.05622 & 3.658 & $\star \star \star$ \\
\hline POS & 0.67587 & 0.14141 & 4.779 & $\star \star \star$ \\
\hline
\end{tabular}

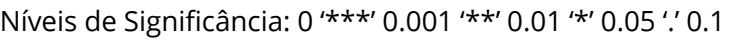

AIC (-1029.327); SBC (-918.7346).

Fonte: resultados da Pesquisa.

Conforme apresenta a Tabela 3, 14 variáveis da pesquisa se mostraram estatisticamente significantes para explicar o Índice de Aprovação das IES na 1a edição do Exame do CFC em 2017. Com exceção da região Sul (em relação à região sudeste), todas as evariáveis acima apresentam significância estatística a pelo menos $5 \%$ (sendo a maioria significante a $0 \%$ ).

Analisando-se os coeficientes de estimação (estimativa), tem-se que as variáveis com maiores coeficientes são mais relevantes para explicar o desempenho médio das IES no Exame do CFC. A primeira variável a ser destacada é a POS. Com o maior coeficiente estimado o alto nível de significância estatística, tal resultado indica que as IES que possuem programas de pós-graduação stricto sensu em Contabilidade, em média, são aquelas que apresentam cursos com os mais altos índices de aprovação no exame do CFC. Este resultado é bastante representativo, pois apenas 3,2\% das IES estudadas ofertam os referidos cursos.

Entende-se por tal resultado que fatores como constante avaliação do MEC (para credenciamento e manutenção dos cursos de pós-graduação), maior qualificação do corpo docente (que geralmente atua na graduação e na pós-graduação) e experiência com pesquisa podem ocasionar uma qualidade superior do ensino ofertado por estas IES, o que refletiria diretamente no processo de aprendizagem dos alunos e, consequentemente, no sucesso destes em testes, avaliações e exames, como é o caso do CFC.

A segunda variável com maior relevância para explicar o desempenho médio das IES no exame do CFC foi a variável da região Norte. A variável se mostra significativa e com coeficiente estimado negativo, revelando que se o curso pertence a uma IES localizada na região Norte do país, menores seriam as chances de aprovação no Exame do CFC.

Do mesmo modo, as regiões Centro-Oeste e Nordeste apresentam coeficientes estimados negativos e significativos em relação ao desempenho das IES localizadas na região Sudeste, indicando também menores chances de aprovação no exame para estudantes de IES pertencentes a amostras localizadas nestas regiões. A única região com coeficiente estimado positivo entre os estatisticamente significativos é a região Sul, o que corresponde a maiores chances de aprovação no exame para egressos de suas IES, com significância estatística a 10\% na primeira edição do exame em 2017. 
O resultado supracitado converge com estudos que analisaram outros exames educacionais. Miranda (2011), por exemplo, ao analisar fatores determinantes para a nota da IES no ENADE de Ciências Contábeis, encontrou resultados indicando que a região Norte apresentou as menores pontuações no Exame em 2009, enquanto as regiões Sul e Sudeste apresentaram os melhores desempenhos.

O ENADE se configura como a próxima variável com coeficiente estimado mais relevante e positivamente significante estatisticamente. Tal variável indica que quanto melhor o desempenho do curso da IES analisada na prova do ENADE, maior a chance de aprovação de seus alunos no Exame de Suficiência da profissão, com significância estatística a $0 \%$. Portanto, se um curso consegue boa pontuação no ENADE, maiores são as chances de seus egressos também terem sucesso no exame do CFC para os cursos que compuseram a amostra desta pesquisa.

A Categoria Acadêmica é, na $1^{\text {a }}$ edição do exame do CFC, a $5^{\text {a }}$ variável mais relevante para explicar o desempenho dos alunos das IES no exame do CFC. Os resultados obtidos sugerem que, se o aluno estudou em uma instituição pública, possui maiores chances de ser aprovado no Exame de Suficiência, para os cursos pesquisados. As estatísticas descritivas já haviam revelado uma maior média de aprovação no Exame de Suficiência das IES públicas, que agora se mostraram positivamente correlacionadas ao desempenho dos cursos analisados no referido exame. Esse resultado é coerente com o encontrado por Ferreira (2015), que verificou que alunos de IES privadas tendem a ter desempenho inferior aos alunos de IES públicas em exames educacionais.

A Variável RUF revelou que os cursos de Contabilidade das IES preferidas pelos empregadores são aqueles que possuem mais egressos aprovados no exame do CFC, dada a sua correlação positiva e significativa a $0 \%$. Sendo assim, alunos de instituições com resultados mais positivos no exame do CFC têm mais chances de pertencerem a cursos vistos como de qualidade pelos empregadores, para os dados da amostra. Esse resultado alinha-se aos de Fogarty, Zimmerman e Richardson (2016), que destacaram a importância de cursos de Contabilidade manterem uma relação positiva com as empresas que compõem o mercado de trabalho da profissão.

Da variável "Organização Acadêmica", o único item que se mostrou significativo na 1ª edição do Exame foi Faculdade. Com coeficiente de estimação negativo, essa variável revelou que os cursos oriundos de IES que são classificadas como "Faculdades" apresentam desempenhos inferiores às Universidades (constante no modelo) no Exame do CFC, entre os cursos pesquisados. Este resultado pode estar relacionado ao processo de criação das IES, uma vez que "Faculdade" se refere ao primeiro estágio de constituição de uma IES, logo, tende a apresentar características menos robustas do que uma IES que já se encontra no patamar de "Universidade" ou "Centro Universitário", o que pode ocasionar diferenças no ensino ofertado a seus egressos. Nesta mesma direção, Abjaud (2014) encontrou desempenho médio inferior nas IES categorizadas como Faculdade, ao avaliar desempenho delas em avaliações institucionais, com base no Censo da Educação Superior.

Os achados relacionados à variável "IN_CAP" revelaram que existe correlação positiva e significativa entre o fato de os alunos serem oriundos de cursos localizados nas capitais dos estados do país e o desempenho destes no exame do CFC, entre as IES pertencentes a amostra. Tal fato pode derivar do nível de urbanização e desenvolvimento econômico que ocorre, primordialmente, na capital dos estados, antes de migrar para as cidades do interior.

A próxima variável analisada foi a "HALO". A proposta dessa variável é verificar se as IES avaliadas globalmente como de excelência correspondem, do mesmo modo, àquelas IES que possuem cursos com melhores resultados no exame do CFC. Em outras palavras, se a IES é tida como de grande qualidade por seus cursos em geral, também forneceria um curso de Contabilidade com melhores índices de aprovação no exame do CFC.

Tal variável foi operacionalizada por meio do IGC, que representa uma avaliação global da IES, como descrito na Tabela 1. A partir da Tabela 3, percebe-se que a variável apresentou coeficiente estimado positivo e significativo na $1^{\text {a }}$ edição do exame, sugerindo, portanto, que as IES tidas como de maior qualidade em sua avaliação global são aquelas que apresentam, do mesmo modo, bons resultados no Exame do CFC para os cursos pesquisados. 
Apresentando significância estatística, mas com coeficiente estimado negativo (apesar de baixo), a variável Regime de Trabalho dos Professores indica que quanto maior a proporção de professores em regime parcial ou integral, menores seriam os índices de aprovação da IES no Exame do CFC. Tal resultado, aparentemente, contraria estudos anteriores que identificaram correlação positiva entre maior carga horária de regime de trabalho docente e melhor desempenho discente em avaliações institucionais (Santos, 2012; Lacerda, 2015).

Entretanto, o resultado é coerente com o encontrado por Wilson (2002), ao estudar determinantes exógenos da performance de estudantes em exames de Finanças. $\mathrm{O}$ autor revelou, do mesmo modo, ser este resultado uma "surpresa", e rejeitou a hipótese inicial do trabalho, que esperava efeito contrário. O não controle de variáveis ao nível dos discentes pode, de alguma forma, ter contribuído para a essa correlação.

A variável relacionada à Titulação Docente (DOC) apresentou significância e coeficiente positivo ao explicar o comportamento da variável dependente. O resultado sugere que egressos de cursos com corpo docente formado por professores com maiores titulações acadêmicas possuem melhores chances de aprovação no exame do CFC. Este resultado vai ao encontro dos achados por Brito (2015), Ferreira (2015), Lemos e Miranda (2014), ao estudarem os fatores determinantes do resultado no Enade. Miranda (2011) revela ainda que as regiões com menos mestres e doutores são as regiões com menores índices no Enade, destacando a região Norte.

Por fim, a variável Infraestrutura apresentou significância estatística na $1^{\text {a }}$ Edição do exame com coeficiente estimado negativo, indicando que quanto melhor a avaliação de infraestrutura da IES, piores são seus índices de aprovação, para a amostra estudada. Esse resultado pode indicar que algumas instituições investem prioritariamente em instalações, como estratégia de atração de discentes, mas que não necessariamente apresentam altos padrões de qualidade de ensino. Outro aspecto que merece destaque é o fato de as IES públicas, muitas vezes, receberem avaliações insatisfatórias no que se refere a sua infraestrutura, em função da escassez de recursos para investimento por parte do governo.

Seguindo a análise dos resultados da regressão principal, a Tabela 4 apresenta as variáveis e suas relações com o índice de aprovação dos egressos das IES da amostra do estudo, na $2^{a}$ edição do exame do CFC em 2017.

Tabela 4

Outputs Regressão Beta Inflacionada em 0 - 2ª Edição 2017

\begin{tabular}{|c|c|c|c|c|}
\hline Variáveis & Estimativa & Erro Padrão & Valor $\mathbf{t}$ & Significância \\
\hline (Intercepto) & -2.161 .858 & 0.152897 & -14.139 & $\star \star \star *$ \\
\hline ENADE & 0.301095 & 0.032995 & 9.125 & $\star \star \star ~$ \\
\hline PROF & 0.003841 & 0.001369 & 2.806 & $\star \star$ \\
\hline REGIM & -0.041893 & 0.018860 & -2.221 & * \\
\hline HALO & 0.180746 & 0.052325 & 3.454 & $\star \star \star$ \\
\hline CAT & 0.482748 & 0.085164 & 5.668 & $\star \star \star$ \\
\hline Dummy_ORG_FAC & -0.102523 & 0.053942 & -1.901 & . \\
\hline Dummy_Reg_CentroOeste & -0.359453 & 0.071232 & -5.046 & $\star \star \star$ \\
\hline Dummy_Reg_Nordeste & -0.281750 & 0.056652 & -4.973 & $\star \star \star ~$ \\
\hline Dummy_Reg_Norte & -0.589614 & 0.085879 & -6.866 & $\star \star \star *$ \\
\hline IN_CAP & 0.076950 & 0.045651 & 1.686 & . \\
\hline RUF & 0.253609 & 0.053534 & 4.737 & $\star \star \star$ \\
\hline POS & 0.445294 & 0.147487 & 3.019 & $\star \star$ \\
\hline
\end{tabular}

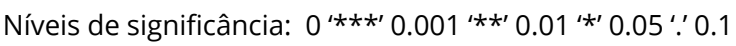

AIC(-1086.345); SBC (-989.5771)

Fonte: resultados da Pesquisa. 
$\mathrm{Na} 2^{\text {a }}$ edição do exame em 2017, encontrou-se significância estatística em 12 variáveis independentes do modelo inicial. Assim como na $1^{\text {a }}$ edição, a maioria é significante estatisticamente a pelo menos 5\%, exceto a variável IN_CAP e Organização Acadêmica Faculdade, que são significantes estatisticamente a $10 \%$, o que ainda explica de maneira razoável o comportamento da variável dependente.

A primeira variável significativa a ser destacada na $2^{\text {a }}$ edição do exame apresenta coeficiente estimado negativo, e é região Norte. Este resultado é semelhante ao encontrado na $1^{\text {a }}$ edição do exame, e, do mesmo modo, as regiões Centro-Oeste e Nordeste seguem apresentando coeficientes estimados negativos e significativos em relação ao desempenho das IES localizadas na região Sudeste, aplicando-se as análises já realizadas.

A Categoria Acadêmica é, na $2^{\mathrm{a}}$ edição do exame do CFC, a $2^{\mathrm{a}}$ variável mais relevante para explicar o desempenho dos alunos das IES no exame. Assim como na $1^{\text {a }}$ edição, o coeficiente estimado é positivo, reforçando a conclusão de que se o aluno estudou em uma instituição pública, suas chances de sucesso no exame profissional são maiores, para os cursos pesquisados.

A variável POS também apresenta significância estatística positiva na $2^{a}$ edição do exame, sendo a terceira variável com maior capacidade de explicação do desempenho dos alunos no exame profissional. Vale destacar novamente sua representatividade, pois, apesar de poucas IES da amostra ofertarem cursos de Pós-Graduação stricto sensu em contabilidade, a variável ainda se mostra significativa e positiva em ambas edições do exame do CFC.

A próxima variável com coeficiente estimado positivo e estatisticamente significativo na $2^{\mathrm{a}}$ edição do exame, em 2017, é a variávelEnade. O resultado é coerente com o encontrado na $1^{\text {a }}$ edição do exame, e reforça a relação existente entre o desempenho de ambos exames.

A Variável RUF, assim como na $1^{\text {a }}$ edição do exame do CFC, apresentou coeficiente positivo e significativo, dando robustez à análise de que as IES contempladas no estudo, com reputação de formar melhores profissionais pela visão dos empregadores, são de fato aquelas que apresentam maior índice de aprovação no Exame de Suficiência da profissão.

$\mathrm{Na} 2^{\text {a }}$ edição do exame, a variável HALO também apresentou significância e coeficiente estimado positivo, reforçando o fato de que IES bem avaliadas pelo IGC possuem maior número de aprovados no CFC, entre as instituições pesquisadas. Da variável "Organização Acadêmica", assim como na $1^{a}$ edição, a única configuração que se mostrou significante é a Faculdade, quando comparada com as universidades. O coeficiente estimado continua sendo negativo, indicando que egressos das Universidades pesquisadas apresentam índices superiores de aprovação no exame.

A variável "IN_CAP" também apresentou resultado semelhante ao da $1^{a}$ edição, sugerindo que o fato de os alunos serem oriundos de cursos localizados nas capitais dos estados brasileiros está correlacionado a melhor desempenho no exame do CFC. Assim como revelado na Tabela 3, a variável Regime de Trabalho dos Professores continua apresentando significância estatística e coeficiente estimado negativo, como já discutidos anteriormente.

Finalmente, a última variável que apresentou significância estatística para explicar o desempenho das IES da amostra do estudo na 2a edição exame do CFC foi o No de Docentes na Instituição. A variável apresenta coeficiente positivo, indicando que quanto maior a quantidade de professores no curso, maiores as chances de aprovação dos alunos no exame do CFC, para as IES estudadas. A maior diversidade de docentes e expertises pode ser um potencial fator explicativo para essa relação verificada, o que sugere que tal diversidade ampliaria as possibilidades de aprendizado e, consequentemente, a qualidade do ensino. Brito (2015) também encontrou essa relação positiva entre número de professores e desempenho dos alunos em exames educacionais. 


\subsubsection{Resultados complementares}

A Regressão Beta inflacionada em 0 e/ou 0 e 1, além do modelo principal, para média, apresenta resultados adicionais acerca dos dados que complementam a análise de influência entre as variáveis estudadas nas duas edições do exame. A Tabela 5 apresenta as estimativas do submodelo para precisão, denotada por $\sigma$, que. ao contrário da variância,indicam a precisão da relação entre os cursos analisados.

Tabela 5

Outputs $\sigma-1^{\text {a }}$ Edição CFC

\begin{tabular}{lcccc}
\hline \multicolumn{1}{c}{ Variáveis } & Estimativa & Erro Padrão & Valor t & Significância \\
\hline (Intercepto) & $-1,54 \mathrm{E}+03$ & $1,02 \mathrm{E}+02$ & -15.087 & $* \star *$ \\
\hline ENADE & $2,26 \mathrm{E}+02$ & $4,13 \mathrm{E}+01$ & 5.471 & $* \star \star$ \\
\hline MAT & $-5,45 \mathrm{E}-01$ & $9,35 \mathrm{E}-02$ & -5.836 & $* \star \star$ \\
\hline RUF & $1,44 \mathrm{E}+02$ & $7,09 \mathrm{E}+01$ & 2.028 & $*$ \\
\hline
\end{tabular}

Níveis de significância: 0 ‘***’ $0.001^{‘ \star \star \prime} 0.01^{‘ \star \prime}$

Fonte: resultados da Pesquisa.

A Tabela 5 revela que três variáveis independentes explicam a homogeneidade do desempenho dos cursos das IES pesquisadas na $1^{\text {a }}$ dição do exame. A quantidade de matriculados por curso apresenta coeficiente estimado negativo e significativo, ou seja, ocasiona maior variação nos resultados dos cursos. Tal achado é compreensível, uma vez que quanto maior o número de alunos no curso, maiores são as chances de resultados diferentes entre aprovados e reprovados no exame, portanto, maior potencial de variação.

A variável ENADE também se mostrou significante, mas com coeficiente de estimação positivo, indicando que quanto maior a nota noEnade, mais resultados homogêneos no exame do CFC é obtido entre as IES pertencentes à amostra. Tal interpretação também é válida para a variável RUF, que, do mesmo modo, apresentou coeficiente estimado positivo e estatisticamente significativo, revelando que a indicação dos cursos pelos empregadores como sendo de qualidade torna os resultados mais próximos no exame do CFC.

Já para a $2^{\text {a }}$ dição do exame, (Tabela 6), as variáveis que apresentaram significância estatística para a precisão dos resultados entre as IES analisadas foram oEnade, a Categoria Administrativa e a quantidade de matriculados no curso. A variável ENADE, diferentemente da relação encontrada nos dados da $1^{\text {a }}$ edição do exame do CFC, apresentou coeficiente estimado negativo, indicando que quanto maior a nota noEnade, maior dispersão entre os resultados no exame de suficiência. Uma possível explicação para essa variação de resultados pode estar relacionada a aspectos vinculados ao perfil dos alunos que realizaram o Exame na $1^{\text {a }}$ e na $2^{\text {a }}$ edições.

Como não foi possível controlar dados referentes aos estudantes por ausência de acesso aos microdados de desempenho nos exames do CFC, não se podem identificar características do corpo discente que ajudem a explicar tal diferença, apesar de ser provável que a variação de desempenho para acesso ao nível superior seja um indicador que, potencialmente, influenciaria o desempenho dos discentes no exame, uma vez que se sabe que estudantes mais bem colocados nos vestibulares ingressam no primeiro semestre letivo do ano e, consequentemente, tendem a fazer o primeiro Exame de Suficiência do ano seguinte a sua conclusão no curso, enquanto que estudantes ingressantes no segundo semestre precisam cursar mais um semestre para estarem aptos à finalização da matriz curricular e, só então, prestarem o exame profissional.

A variável Categoria Acadêmica, conforme resultados da Tabela 6, também se mostrou significativa e com coeficiente estimado negativo, indicando que o fato de a IES ser privada, aumenta a dispersão do desempenho no Exame do CFC entre os cursos pesquisados. Por sua vez, a variável MAT no segundo exame analisado, apesar de apresentar significância estatística, possui um coeficiente estimado positivo bem próximo de zero, o que revela sua menor relevância na precisão dos resultados da segunda edição. 
Tabela 6

Outputs $\sigma-2^{a}$ Edição CFC

\begin{tabular}{lcccc}
\hline \multicolumn{1}{c}{ Variáveis } & Estimativa & Erro Padrão & Valor t & Significância \\
\hline (Intercepto) & 32.997 .442 & 0.1609124 & 20.506 & $* * *$ \\
\hline ENADE & -0.3072978 & 0.0662832 & -4.636 & $* * *$ \\
\hline CAT & -0.5530677 & 0.1618758 & -3.417 & $* * *$ \\
\hline MAT & 0.0008370 & 0.0002422 & 3.455 & $* * *$ \\
\hline
\end{tabular}

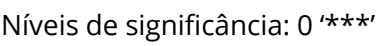

Fonte: resultados da Pesquisa.

A Tabela 7 apresenta os coeficientes do submodelo para o parâmetro de mistura $v$, ou seja, as variáveis que possuem relação com a probabilidade de ocorrência de $0 \%$ de aprovação das IES no exame do CFC

Tabela 7

Outputs $v$ - 1a Edição CFC

\begin{tabular}{lcccc}
\hline \multicolumn{1}{c}{ Variáveis } & Estimativa & Erro Padrão & Valor t & Significância \\
\hline ENADE & -110.920 & 0.33709 & -3.291 & $*$ \\
\hline INFR & 0.48405 & 0.19346 & 2.502 & $*$ \\
\hline PROF & -0.15199 & 0.03697 & -4.112 & $* * *$ \\
\hline IN_CAP & -140.150 & 0.64755 & -2.164 & $*$ \\
\hline
\end{tabular}

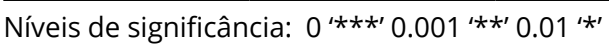

Fonte: resultados da Pesquisa.

O coeficiente estimado com maior representatividade é o da variável IN_CAP e, por ser negativo, revela que o fato de um curso pertencer a uma IES que está localizada em capitais dos estados brasileiros apresentou menores chances de não ter nenhum aluno aprovado na $1^{\text {a }}$ edição do exame do CFC, para os dados da amostra. Do mesmo modo, as variáveis ENADE e PROF apresentam também coeficiente estimado negativo e bastante elevados. Esse resultado indica que quanto melhor o desempenho dos alunos das IES noEnade, menores as chances de o curso não ter nenhum aprovado no exame. Por sua vez, a variável PROF revela que quanto maior o número de professores, torna-se mais improvável que a IES tenha um índice de aprovação de 0\% no Exame de Suficiência.

Entretanto, a variável Infraestrutura apresentou coeficiente significativo e positivo. Isso indica que quanto melhor a infraestrutura da IES, na percepção dos discentes, mais chance de haver $0 \%$ de aprovados no Exame de Suficiência, para as IES que compuseram a amostra da pesquisa.

Apesar de possuir IES com 100\% de aprovação na $1^{a}$ edição do exame do CFC, o submodelo para o parâmetro de mistura $\tau \tau$ revelou que nenhuma das variáveis se mostrourelevante para explicar a chance de todos os alunos serem aprovados no exame, para os dados da amostra.

Para a $2^{a}$ edição do exame do CFC, foi executada a Regressão Beta inflacionada em 0. A Tabela 8 apresenta os coeficientes do submodelo para o parâmetro de mistura $v v$,evidenciando as variáveis que se mostraram significativas para explicar a ocorrência de $0 \%$ de Aprovação das IES no exame do CFC. 
Tabela 8

Outputs $v$ - 2a Edição 2017

\begin{tabular}{lcccc}
\hline \multicolumn{1}{c}{ Variáveis } & Estimativa & Erro Padrão & Valor t & Significância \\
\hline REGIM & 0.473732 & 0.222125 & 2.133 & $*$ \\
\hline HALO & -1.151 .640 & 0.343107 & -3.357 & $* * *$ \\
\hline IN_CAP & -1.422 .848 & 0.771691 & -1.844 &. \\
\hline MAT & -0.011766 & 0.004032 & -2.918 & $* *$ \\
\hline
\end{tabular}

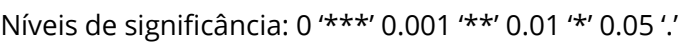

Fonte: resultados da Pesquisa.

A partir dos resultados apresentados, percebe-se que as variáveis de maior relevância são a variável HALO e a variável IN_CAP. A variável HALO, que apresentou coeficiente estimado negativo, revela que quanto maior a avaliação global de uma IES, menores são suas chances de apresentar $0 \%$ de aprovação no exame do CFC.

A variável IN_CAP, que também apresentou coeficiente estimado negativo, indica que o fato de a IES estar localizada em uma capital reduz as chances de ocorrência de $0 \%$ de aprovação no Exame de Suficiência, para as instituições pesquisadas. Por sua vez, a variável MAT também apresentou coeficiente estimado negativo e estatisticamente significativo, revelando que quanto maior o número de alunos matriculados, menores as chances de a IES não conseguir nenhuma aprovação no Exame.

Finalmente, a variável REGIM sugere que quanto maior o número de professores em regime integral e parcial, maiores as chances das IES que compuseram a amostra da pesquisa apresentar índice de $0 \%$ de aprovação. Conforme já analisado na discussão da regressão principal, este resultado contraria estudos que anteriormente identificaram correlação positiva entre maior carga horária de regime de trabalho docente e melhor desempenho discente em exames educacionais.

Faz-se importante destacar que o desenho da pesquisa abarcou variáveis que representam características institucionais da IES e, não variáveis relacionadas às características dos discentes dos cursos. Estas últimas, por não serem controladas nesta pesquisa por indisponibilidade de dados, podem exercer influência sobre o resultado apresentado.

A literatura ainda revela que características discentes possuem forte influência no desempenho obtido em exames, porém tais características são menos passíveis de controle e gestão por parte das instituições. Portanto, conhecer fatores institucionais que podem, potencialmente, influenciar o sucesso de egressos no exame profissional da área contábil pode auxiliar os gestores dos cursos em suas decisões acadêmicas.

\section{Considerações Finais}

A avaliação de programas educacionais deve ser um processo contínuo com o objetivo de melhor conhecer aspectos positivos e negativos acerca do objeto avaliado, possibilitando que, ao se identificarem os fatores que contribuem para o bom desempenho dos discentes, estes sejam fortalecidos, enquanto medidas corretivas possam ser aplicadas aos fatores, passíveis de mudança, que pouco contribuem para a formação do discente.

O desenho metodológico da presente pesquisa adicionou, ao conjunto de variáveis independentes normalmente utilizadas nos estudos revisados, algumas variáveis exploratórias, objetivando verificar se elas influenciariam o desempenho dos estudantes no exame do CFC.

A variável Pós apresentou destacada relevância no desempenho dos estudantes no exame, pois são poucas as IES que possibilitam a continuidade do estudo em Contabilidade por meio de programas de mestrado e doutorado no Brasil. Mas apesar desse número reduzido, essa variável se mostra altamente significante e de maneira positiva na amostra pesquisada. 
Entende-se que IES com programas de pós-graduação stricto sensu em Contabilidade representam instituições geralmente com maior tempo de fundação, corpo docente mais especializado e com avaliações regulares do MEC. Essas características reforçam a ideia de que os programas de pós-graduação não só possibilitam o desenvolvimento da Contabilidade no Brasil em função da pesquisa, como também beneficiam a formação de base do profissionalda Contabilidade.

A variável RUF, também exploratória, requer do mesmo modo atenção por demonstrar que os profissionais do mercado podem estar atentos ao desempenho dos alunos das diversas IES no exame profissional, e isso é refletido ao se perceber que as IES preferidas pelos empregadores, no momento da contratação de profissionais da contabilidade, são aquelas com os melhores desempenhos no exame do CFC, para os dados da amostra. Sendo assim, a elevação da notoriedade do curso no mercado profissional poderá estar relacionada a melhores índices de aprovação no exame profissional.

Finalmente, traz-se à discussão a variável IN_CAP, que revelou que, entre os cursos pesquisados, aqueles de IES localizadas nas capitais dos estados possuem maiores índices de aprovação, o que pode ser remetido ao desenvolvimento econômico que geralmente se dá primordialmente nas regiões metropolitanas, logo, atraindo maior demanda pela formação de nível superior, o que gera maior concorrência no processo seletivo, assim como maior cobrança do mercado por bons profissionais, dado o maior contingente disponível para as vagas.

O presente trabalho só foi possível a partir de 2017, quando o Conselho Federal de Contabilidade iniciou a divulgação do resultado por IES. Portanto, seus resultados estão entre os esforços iniciais que buscam melhor entender aspectos relacionados ao sucesso dos bacharéis em Ciências Contábeis no exame de certificação profissional brasileiro.

Por meio dos resultados gerados, este estudo contribui também com os gestores das IES e coordenadores de cursos ao revelar possíveis atributos institucionais que aumentariam as chances de sucesso dos seus egressos no Exame de Suficiência. Assim, tais gestores podem implementar ações que visem otimizar as características identificadas como direcionadoras de maior percentual de aprovação no exame, o que se espera resultar também em melhoria da formação dos futuros profissionaisda contabilidade.

Nos últimos anos, as taxas de aprovação dos egressos de cursos de Ciências Contábeis no exame profissional do CFC têm se mostrado muito aquém do desejável e, paralelamente, houve um considerável aumento no número de autorizações e reconhecimentos de cursos de Contabilidade (nas modalidades "presenciais" e "a distância") no Brasil.

Tal expansão, que em sua proposta é bastante positiva por aumentar a acessibilidade e gerar oportunidades para diferentes camadas sociais e regiões do país, precisa ser realizada de maneira criteriosa por parte dos órgãos responsáveis e instituições de ensino, de modo que os profissionais oriundos dessas IES atendam às expectativas do mercado de trabalho, formando bacharéis que reúnam as competências e habilidades esperadas ao desempenho da atividade contábil, o que, aparentemente, não vem ocorrendo pelo que se pode depreender dos resultados das últimas edições do Exame de Suficiência.

Impende ainda salientar que análises mais robustas acerca do desempenho dos egressos no exame requerem o acesso aos microdados dos candidatos, ainda não disponibilizados pelo CFC, uma vez que as regressões apontaram evidências que contrariam a literatura, conforme já discutido, que poderiam ser mais bem explicadas a partir da inclusão de variáveis ao nível do estudante.

Quanto às limitações da pesquisa, faz-se importante citar que foram analisados apenas os cursos das Instituições de Ensino Superior que possuíam alunos inscritos no Exame de Suficiência nas duas edições de 2017, o que não abrange todos os cursos de Ciências Contábeis em atividade no país. Outra limitação que merece destaque é que se reconhece que estudantes formados em diferentes períodos, nos quais as IES poderiam possuir diferentes características, podem ter feito o exame em 2017.1 e 2017.2, e foram "rotulados" com os atributos atuais da instituição. 
Por fim, para futuras pesquisas, sugerem-se novas análises com maior recorte temporal. Além disso, sugere-se a inclusão das características dos discentes, que podem apresentar diferentes relações com o seu desempenho no Exame do CFC, mas, para tanto, espera-se que o Conselho Federal de Contabilidade amplie sua política de acesso aos dados do exame.

\section{Referências}

Abjaud, J.V.M. (2014). Fatores de análise de desempenho determinantes das IES e Unidades de ensino superior brasileiras: uma análise das relações entre as variáveis do Censo da Educação Superior e Demográfico. Dissertação Mestrado, Universidade FUMEC, Belo Horizonte, MG, Brasil. Recuperado de http:// www.fumec.br/revistas/sigc/article/view/2383

Andriola, W. B. (2009). Fatores institucionais associados aos resultados do Exame Nacional de Desempenho Estudantil (ENADE). Revista Iberoamericana sobre Calidad, Eficacia y Cambio en Educación, 7 (1), 22-49. Recuperado de http://www.rinace.net/reice/numeros/arts/vol7num1/art2.pdf.

Barilla, A. G., Jackson, R. E., \& Mooney, J. L. (2008). The CPA Exam as a Postcurriculum Accreditation Assessment. Journal of Education for Business, 83(5), pp.270-274.Recuperado de https://www. tandfonline.com/toc/vjeb20/current. doi: https://doi.org/10.3200/JOEB.83.5.270-274

Bline, D. M., Perreault, S., \& Zheng, X. (2016). Do Accounting Faculty Characteristics Impact CPA Exam Performance? An Investigation of Nearly 700,000 Examinations. Issues in Accounting Education, 31(3), pp.291-300. Recuperado de https://aaajournals.org/doi/10.2308/iace-51227. doi: https://doi. org/10.2308/iace-51227.

Briggs, G. P., \& He, L. (2012). The 150 Credit-hour Requirement and CPA Examination Pass Rates-A Four Year Study. Accounting Education, 21(1), pp. 97-108. Recuperado de https://aaajournals.org/ doi/10.2308/iace-51227. doi: https://doi.org/10.1080/09639284.2011.611345

Brito, T. F. (2015). Corpo docente: fatores determinantes do desempenho discente no ENADE. (Dissertação Mestrado), Universidade de São Paulo, São Paulo,SP,Brasil. Recuperado de https://www.teses.usp. br/teses/disponiveis/12/12139/tde-21032016-115045/publico/CorrigidoTainaBrito2015.pdf. doi: 10.11606/D.12.2016.tde-21032016-115045

Bugarim, M. C. C., Rodrigues, L. L., Pinho, J. C. C., \& Machado, D. Q. (2014). O desempenho dos profissionais de contabilidade no exame de suficiência do CFC: uma análise de conglomerados regionais. Revista de Contabilidade e Organizações, 8(22), pp.60-71. Recuperado de http://www. revistas.usp.br/rco/article/view/61176. doi:10.11606/rco.v8i22.61176

Bunker, R., \& Harris, D. (2014). Online accounting degrees: An empirical investigation of CPA exam success rates. Journal of Business and Accounting, 7(1), pp.86-93. Recuperado de https://www.questia.com/ library/journal/1P3-3517220261/online-accounting-degrees-an-empirical-investigation.

Conselho Federal de Contabilidade - CFC. (2016). NBC PG 12 (R2). Educação Profissional Continuada. Recuperado de: <http://cfc.org.br/wpcontent/uploads/2016/12/NBCPG12R2.pdf >.

Conselho Federal de Contabilidade - CFC. (2017). O Conselho. Recuperado de: <http://cfc.org.br/ oconselho/>.

Conselho Federal de Contabilidade - CFC. (2019). Resultado final por Exame e UF. Recuperado de: $<$ https://cfc.org.br/wp-content/uploads/2019/08/Relat\%C3\%B3rios-Estat\%C3\%ADsticosEdicao-I.2019.pdf $>$. 
Cruz, A. J. (2012). Desempenho dos alunos no ENADE de 2009: um estudo empírico a partir do conteúdo curricular dos cursos de Ciências Contábeis no Brasil. (Dissertação Mestrado), FUCAPE Business School, Vitória, ES, Brasil. Recuperado de http://www.fucape.br/_public/producao_cientifica/8/ Disserta\%C3\%A7\%C3\%A3o\%20Alair\%20Jos\%C3\%A9\%20da\%20Cruz.pdf.

Ferrari, S. L. P., \& Cribari-Neto, F. (2004). Beta Regression for Modeling Rates and Proportions. Journal of Applied Statistics, 31(7), pp.799-815. Recuperado de https://www.tandfonline.com/doi/abs/10. 1080/0266476042000214501.

Ferreira, M. A. (2015). Determinantes do desempenho discente no ENADE em cursos de Ciências Contábeis. (Dissertação Mestrado), Universidade Federal de Uberlândia, Uberlândia, MG, Brasil. Recuperado de https://repositorio.ufu.br/handle/123456789/12620.:

Fogarty, T. J., Zimmerman, A. B., \& Richardson, V. J. (2016). What do we mean by accounting program quality? A decomposition of accounting faculty opinions. Journal of Accounting Education, 36(C), pp.16-42. Recuperado de https://ideas.repec.org/a/eee/joaced/v36y2016icp16-42.html.

Instituto Nacional de Estudos e Pesquisas Educacionais Anísio Teixeira (2007). Sinopse Estatística da Educação Superior 2006. Recuperado de: <http://portal.inep.gov.br/we/guest/sinopses-estatisticasda-educacao-superior $>$.

Instituto Nacional de Estudos e Pesquisas Educacionais Anísio Teixeira (2019). Sinopse Estatística da Educação Superior 2018. Recuperado de: <http://download.inep.gov.br/informacoes_estatisticas/ sinopses_estatisticas/sinopses_educacao_superior/sinopse_educacao_superior_2018.zip>.

Lacerda, L. L. V. (2015). Sistema Nacional de Avaliação da Educação Superior: sistema de avaliação ou Exame de desempenho? (Tese Doutorado), Universidade do Vale do Itajaí, Santa Cantarina, Brasil.

Lemos, K. C. S., \& Miranda, G. J. (2014). Alto e Baixo Desempenho no ENADE: que variáveis explicam? $V$ Congresso UFSC de Controladoria e Finanças e Iniciação Científica em Contabilidade. Recuperado de http://dvl.ccn.ufsc.br/congresso/anais/5CCF/20140425111637.pdf.

Lepchak, A., Oliveira, A. Jr. de., Fragalli, A., \& Scarpin, J. E. (2016). A avaliação da Educação superior: um estudo sobre os determinantes de desempenho. Revista Ibero-Americana de Estudos em Educação, 11(3), pp.1111-1131. Recuperado de https://periodicos.fclar.unesp.br/iberoamericana/article/ view/6288 doi: https://doi.org/10.21723/riaee.v11.n3.6288

Miranda, G. J. (2011). Relações entre as qualificações do professor e o desempenho discente nos cursos de graduação em Contabilidade no Brasil. (Tese Doutorado), Universidade de São Paulo, São Paulo, Brasil. Recuperado de https://www.teses.usp.br/teses/disponiveis/12/12136/tde-16032012-190355/ pt-br.php doi: 10.11606/T.12.2011.tde-16032012-190355

Moreira, A. M. A. (2010). Fatores institucionais e desempenho acadêmico no ENADE: um estudo sobre os cursos de Biologia, Engenharia Civil, História e Pedagogia. (Tese Doutorado), Universidade de Brasília, Brasília, DF, Brasil. Recuperado de https://repositorio.unb.br/handle/10482/8663? mode=full.

Morgan, J., Bergin, J. L., \& Sallee, L. (2008). An investigation of the relationship between AACSB business school accreditation and CPA exam success rates. Journal of Business \& Leadership, 4(1), pp.20-32. Recuperado de https://pdfs.semanticscholar.org/65d3/f4d211f94ea556baefcfd175f25f9ae22e34. pdf doi:

Morgan, J., Bergin, J. L., \& Sallee, L. (2012). Three Types of Business School Accreditation and their Relationships to CPA Exam Scores of Graduates. Advances in Business Research, 3(1), pp.25-35. Recuperado de http://journals.sfu.ca/abr/index.php/abr/article/view/82/56 
Nossa, V. (1999). Ensino da contabilidade no Brasil: uma análise crítica da formação do corpo docente. São Paulo, 1999. Dissertação (Mestrado) - Faculdade de Economia, Administração e Contabilidade (USP). Recuperado de http://www.fucape.br/_public/producao_cientifica/6/Dissertacao\%20 Valcemiro\%20\%282\%29.pdf.

Oliveira Filho, J. A. D. (2010). Controle Interno e Externo da Gestão Pública. Brasília, Brasil: AVM Instituto.

Ospina, R. \& Ferrari, S.L.P. (2010). Inflated beta distributions. Statistical Papers. 51: 111. Recuperado de https://www.researchgate.net/publication/1889063_Inflated_Beta_Distributions doi: DOI: 10.1007/s00362-008-0125-4

Pandolfi, C. (2017). Modelo de mensuração da importância das variáveis do censo da Educação Superior, Censo demográfico e os indicadores de qualidade das instituições de ensino superior. (Tese Doutorado), Universidade Federal do Rio Grande do Sul, Rio Grande do Sul, Brasil. Recuperado de https://www. lume.ufrgs.br/handle/10183/156820

Ranking Universitário Folha (RUF). (2017). Entenda o Ranking Universitário. Folha de São Paulo. Retrieved from: <http://ruf.folha.uol.com.br/2017/ranking-de-cursos/ciencias-contabeis/>.

Rodrigues, L. L., Pinho, C., Bugarim, M. C., Craig, R., \& Machado, D. (2018). Factors affecting success in the professional entry exam for accountants in Brazil. Accounting Education: An International Journal, 27(1), 48-71. https://doi.org/10.1080/09639284.2017.1361851

Saes, F. A. M., \& Cytrynowicz, R. (2001). O ensino comercial na origem dos cursos Superiores de economia, contabilidade e administração. Revista Álvares Penteado. São Paulo, 3(6), pp. 37-59. Recuperado de https://repositorio.usp.br/item/001226774

Santos, N. A. (2012). Determinantes do desempenho acadêmico dos alunos dos cursos de Ciências Contábeis. (Tese Doutorado), Universidade de São Paulo, São Paulo, SP, Brasil. Recuperado de https://www. teses.usp.br/teses/disponiveis/12/12136/tde-11062012-164530/pt-br.php doi: 10.11606/T.12.2012. tde-11062012-164530.

Silva, E. M. D. (2004). A Formação e o perfil dos egressos dos cursos de Ciências Contábeis do município de Vitória. Dissertação de Mestrado, FUCAPE Business School, Vitória, Espírito Santo, Brasil. Recuperado de http://www.fucape.br/_public/producao_cientifica/8/Dissertacao\%20Elcy\%20 Militao.pdf

Wilson, A. (2002). Exogenous Determinants of Student Performance in First Finance Classes. Financial Decisions, 14(1), pp.1-15. Recuperado de https://pdfs.semanticscholar.org/177f/ d4b135983d8b471a767fe73a40f9a016fc99.pdf 